\title{
Grinding with patterned grinding wheels
}

\author{
Denkena, B. ${ }^{1}$, Grove, T. $^{2}$, Göttsching, T. $^{3 *}$ \\ ${ }^{1,2,3}$ Leibniz Universität Hannover, Institute of Production Engineering and Machine Tools, An der Universität 2, 30823 Garb- \\ sen, Germany, \\ *Corresponding author; E-Mail address: goettsching@ifw.uni-hannover.de
}

\begin{abstract}
Grinding is one of the most important manufacturing processes, especially when high surface qualities have to be realized or if hard or brittle materials have to be machined. Often the grinding performance is limited by workpiece failure due to a high thermal load in the contact zone. Therefore structured or patterned grinding wheels are frequently used to reduce the thermal load in the contact zone. In this paper a new patterning method will be introduced by using a fly-cutting kinematic for the structuring process. In face grinding experiments the patterned grinding wheels showed great potential to enhance the overall grinding performance by significantly decreasing process forces and grinding burn. The reduction of the thermal load in the contact zone can be explained by an improved coolant flow through the contact zone, which was measured with a specially designed coolant collecting bin.
\end{abstract}

Keywords: Grinding, patterning, fly-cutting, coolant flow

\section{Introduction}

Grinding is one of the most important manufacturing processes, especially when high surface qualities have to be realized or if hard or brittle materials have to be machined [1]. Often the grinding performance is limited by workpiece failure due to a high thermal load in the contact zone. When grinding with vitrified bonded aluminum oxide grinding wheels up to $75 \%$ of the mechanical energy is converted into heat that diffuses directly into the work piece [2]. In recent years much research has focused on reducing the heat in the contact zone by grinding with new kinds of grinding tools with a modified grinding wheel topography. The grinding tools have a structured or segmented topography, specially manufactured for these applications $[3,4,5$, 6]. Other researchers used special dressing methods, such as new kinds of profile rollers or laser ablation to structure the grinding wheel topography [7, 8]. Parallel, the use of structured or rather patterned grinding wheels has been investigated for the manufacturing of textured surfaces [9, 10]. The grinding wheels' patterns are transferred to the workpiece by face, or the more common application cylindrical grinding. The patterns reduce the friction of a tribological system by increasing the oil retention capacity, which enables the application of finely honed surfaces [11]. A flexible method for creating a patterned grinding wheel with large scaled patterns was designed by Oliveira et al. by employing a controlled piezo excited dresser [12]. Oliveira also focused on enhancing the grinding performance by using such kind of grinding wheel in one of his researches [12].

In summary, most of the concepts for patterned or structured grinding wheels require non-standard grinding tools or a cost- and time-intensive manufacturing process for creating a patterned grinding wheel topography. Given that today's manufacturing processes have to be highly flexible in order to machine customized parts with a large geometrical variety, the introduced concepts do not meet these requirements [13]. Therefore an innovative method for the machining of patterns into the grinding wheel topography in a flexible and productive way by using fly-cutting kinematics will be presented in this paper. The geometrical and kinematic contact conditions during patterning will be explained and process characteristics will be introduced. Face grinding experiments will be conducted in order to analyze the overall potential of enhancing the grinding performance by means of patterning. In further experiments the pattern arrangement and orientation will be varied and different tool specifications regarding grain size, texture and bonding strength will be used. Finally the grinding wheel wear will be measured and correlated with different pattern densities.

\section{Experimental setup}

In order to investigate the potential of patterned grinding wheels for enhancing the overall process efficiency, grinding experiments were conducted. The experiments were carried out on the Blohm Profimat 307 face grinding machine already utilized for the patterning process. A vitrified 
bonded aluminum oxide grinding wheel with grain sizes of 80 mesh was used. Before each grinding experiment the wheel was similarly dressed with a multiple grain dresser with an overlapping ratio of $\mathrm{U}_{\mathrm{d}}=8$ and a single dressing depth of $\mathrm{a}_{\mathrm{ed} \text {,single }}=5 \mu \mathrm{m}$. The experiments with a variation of the tool specification, described in chapter 6 , were conducted with form roller dresser. The patterning was carried out after dressing and will be explained in the next chapter in more detail. The ground workpiece material was a hardened tool steel (X155CrVMo, 64 HRC). For every experiment a total material volume of $\mathrm{V}_{\mathrm{w}}=4000 \mathrm{~mm}^{3}$ was ground. During the grinding process forces were measured with a Kistler dynamometer type 9257B. After the experiments the workpiece surface and subsurface were analyzed by measuring the surface roughness, induced residual stresses with a diffractometer and the grinding burn intensity.

In order to investigate if patterned grinding wheels enhance the coolant flow through the contact zone, analogy experiments were conducted. To quantify the amount of coolant that is transported through the contact zone a setup with a coolant collecting bin was developed. The experimental setup is illustrated in Fig. 1. The grinding wheel rotates inside of a coolant bin that is fixed to the spindle cage. A rubber sealing prevents coolant from leaving or entering the box from the outside. The coolant is directly splashed into the contact zone with a total flow rate of $\dot{\mathrm{V}}_{\text {nozzle }}=21.4 \mathrm{l} / \mathrm{min}$. The coolant nozzle is clamped to a guidance to guarantee constant coolant conditions for every experiment, especially when dressing or patterning has to be conducted in between. The coolant can only enter the coolant bin through the gap between tool and workpiece and exits the box through two vents into a measuring cup. The collected coolant volume quantifies the capability of transporting coolant through the contact zone of patterned and non-patterned grinding wheels. The grinding is conducted as a plunge grinding operation. The advantage of this analogy grinding test is that the distance between workpiece and coolant nozzle stays constant, which allows a reproducible measurement of the coolant flow. The process motions and parameters from face grinding are transferred to that process kinematic. Grinding speed $\left(\mathrm{v}_{\mathrm{s}}\right)$ and feed rate $\left(\mathrm{v}_{\mathrm{f}}\right)$ can be adjusted by the machine control. Different sample widths $\left(\mathrm{w}_{\mathrm{s}}\right)$ create different geometric contact lengths $\left(1_{\mathrm{g}}\right)$, which is similar to a variation of the infeed $\left(a_{\mathrm{e}}\right)$ in face grinding.
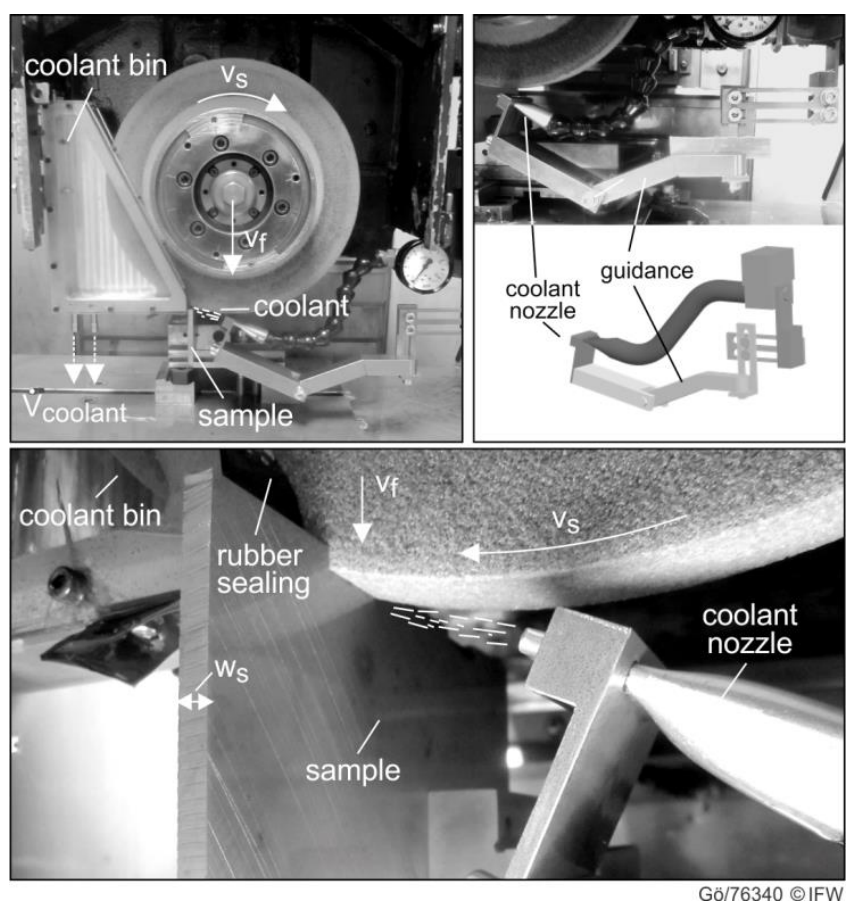

Fig. 1. Experimental setup for measuring the coolant flow

\section{Patterning with fly-cutting kinematic}

The patterning is conducted with a specially manufactured disc with single diamonds (quantity $\mathrm{n}_{\text {diam }}$ ) placed along the circumference. This disc is connected to a conventional dressing spindle. The experimental patterning setup is illustrated in Fig. 2. The patterning spindle (Dr. Kaiser, CF72, $\mathrm{n}_{\max }=30,000 \mathrm{rpm}$ ) and the patterning tool are placed beneath the grinding wheel, such as a standard form roller. The grinding machine is a Blohm Profimat 307 face grinder that is equipped with a rotary encoder for measuring the exact grinding wheel frequency $\left(n_{s}\right)$. The frequency of the patterning tool $\left(\mathrm{n}_{\text {tool }}\right)$ is adjusted to that frequency by multiplying $\mathrm{n}_{\mathrm{c}}$ with any integer. This multiplication determines the number of patterns along the grinding wheel circumference. Since the frequency of the patterning spindle is adjustable to $\pm 1 \mathrm{~min}^{-1}$ it can be easily adapted to the grinding wheel frequency. Before each grinding experiment the topography of the grinding wheel is renewed by a dressing process with a multiple grain dresser.

By adjusting the velocities of grinding wheel and patterning tool $\left(\mathrm{v}_{\mathrm{s}}\right.$ and $\left.\mathrm{v}_{\text {tool }}\right)$, as well as the depth of patterning cut $\left(\mathrm{a}_{\mathrm{ed}}\right)$ and the feed rate $\left(\mathrm{v}_{\mathrm{f}}\right)$, the patterning can be conducted. The discontinuous machining of just a single cutting edge as well as the overlapping of two moving directions enables the production of single patterns on the grinding wheel surface. 

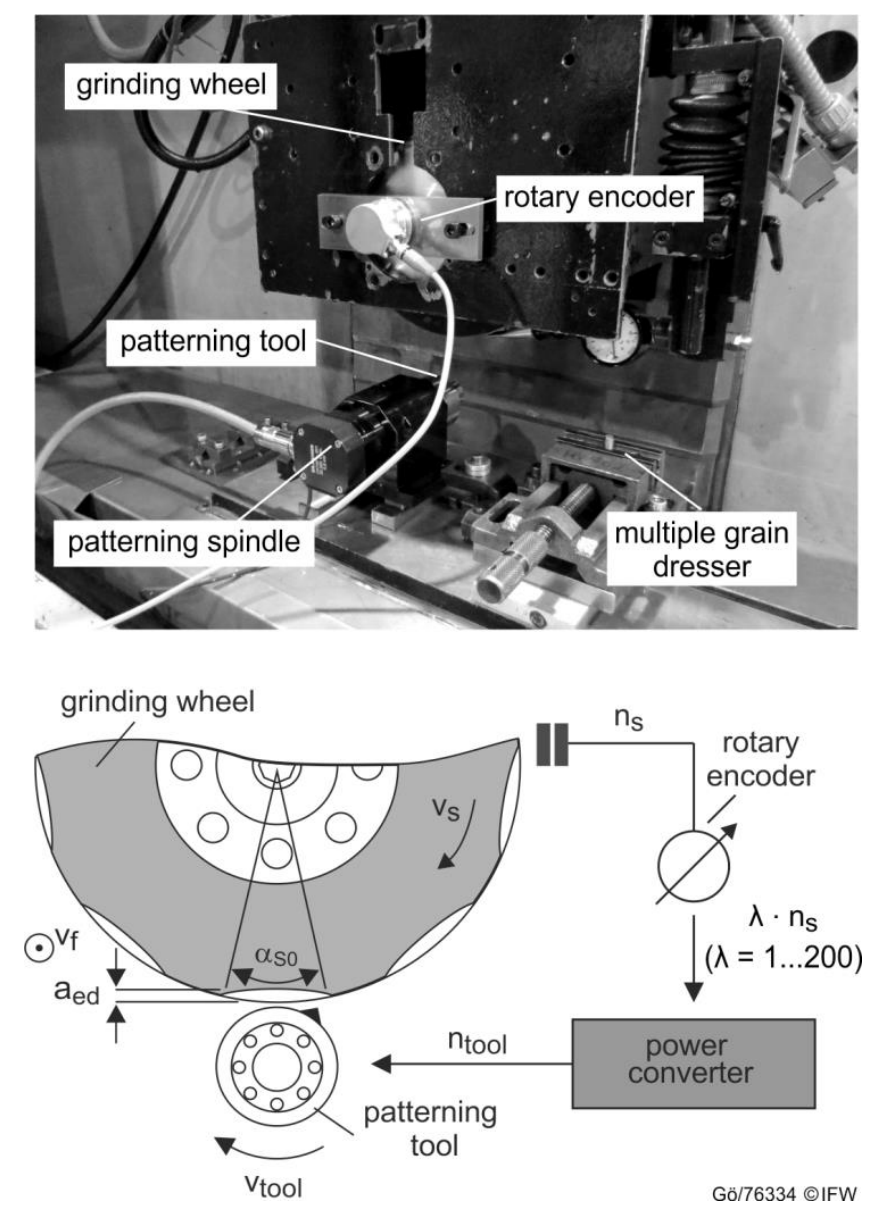

Fig. 2. Experimental patterning setup

The pattern length $\left(l_{\mathrm{pat}}\right)$ is primarily influenced by the patterning tool radii $\left(r_{s}\right.$ and $\left.r_{\text {tool }}\right)$ as well as the relative speed between grinding wheel and cutting tool. According to Grün the pattern length is calculated as follows [14]:

$$
l_{p a t}=\sqrt{2 * r_{s}^{2} *\left(1-\cos \left(\alpha_{s}\right)\right)}
$$

With $\alpha_{\mathrm{s}}$ being the engagement angle $\alpha_{\mathrm{s} 0}$ between patterning tool and grinding wheel multiplied with the relative speed. The positive and negative sign indicate the relative patterning direction regarding the grinding wheel speed (+: counter-rotating / -: co-rotating):

$$
\alpha_{s}=\left(1 \pm \frac{n_{S}}{n_{\text {tool }}} * \frac{r_{s}}{r_{\text {tool }}}\right) * \alpha_{S 0}
$$

The engagement angle $\alpha_{\mathrm{S} 0}$ is derived from the contact conditions by using trigonometry:

$$
2 * \arccos \left(\frac{\left(r_{s}+r_{\text {tool }}-a_{e}\right)^{2}+\left(r_{s}\right)^{2}-r_{\text {tool }}^{2}}{2 *\left(r_{s}+r_{\text {tool }}-a_{e}\right) *\left(r_{s}\right)}\right)
$$

Another process parameter influencing the pattern length $\left(l_{\text {pat }}\right)$ is the patterning depth $\left(a_{\text {pat }}\right)$, which is identical with the depth of cut $\left(\mathrm{a}_{\mathrm{ed}}\right)$ of the patterning process. An increased depth also increases the pattern width $\left(b_{p a t}\right)$, due to the conical tool profile, as well as to a longer contact length between tool and grinding wheel. The patterns that can be machined with this method have a length of about $1_{\text {pat }}=3-$ $7 \mathrm{~mm}$ and a width of $b_{\text {pat }}=0.2-0.5 \mathrm{~mm}$, when the depth of cut is set $\mathrm{a}_{\mathrm{ed}}=20-100 \mu \mathrm{m}$. In Fig. 3 a vitrified bonded silicon carbide grinding wheel with a dense texture and a patterned topography is shown for visualizing the patterned topography.

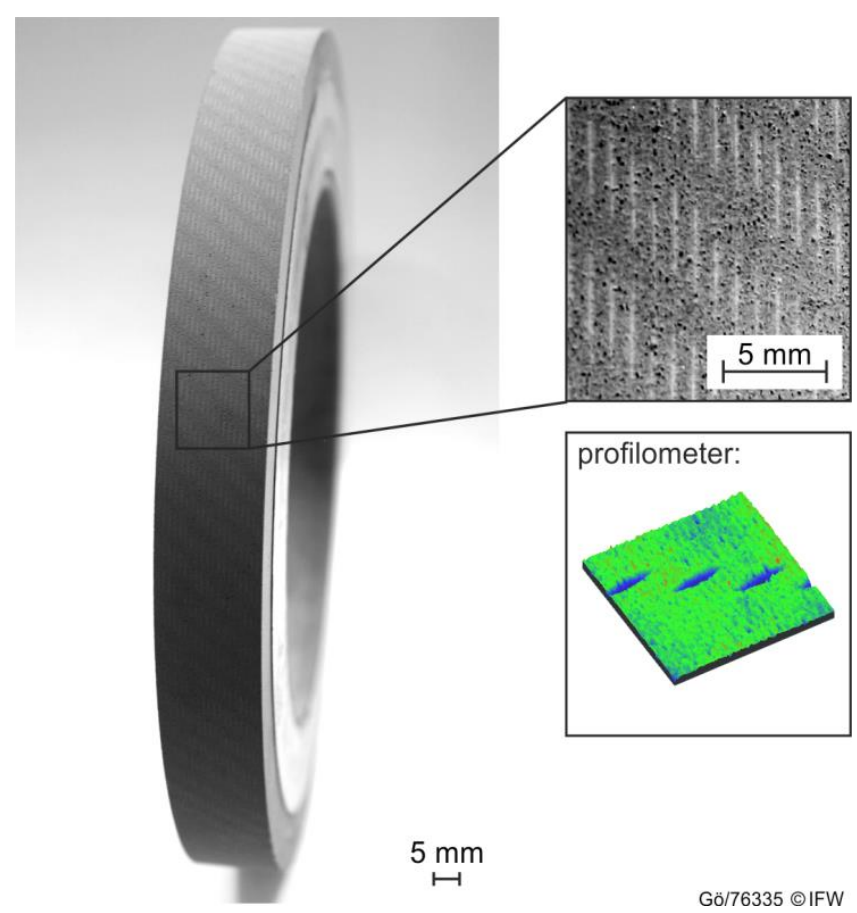

Fig. 3. Patterned grinding wheel

The pattern size is directly influenced by the described process parameters. The frequency ratio $(\lambda)$ between grinding wheel rotational frequency $\left(\mathrm{n}_{\mathrm{s}}\right)$ and tool rotational frequency $\left(\mathrm{n}_{\text {tool }}\right)$ determines the number of patterns that is machined along the grinding wheel circumference. The tool trajectories of a single grinding wheel revolution with a frequency ratio of 8 and 32 are schematically illustrated in Fig. 4 (upper part) for a counter-rotating patterning mode. If the frequency ratio increases, more and shorter patterns are machined. By increasing the axial feed motion of the patterning tool $\left(\mathrm{v}_{\mathrm{f}}\right)$ the number of patterns can also be minimized (Fig. 4, bottom part). More tool trajectories repeat itself with a defined offset between each other and therefore increase the pattern density. The area of the grinding wheel that is not patterned is called effective contact area $\left(\mathrm{A}_{\text {eff }}\right)$, as this area will be in direct contact with the workpiece while grinding. 


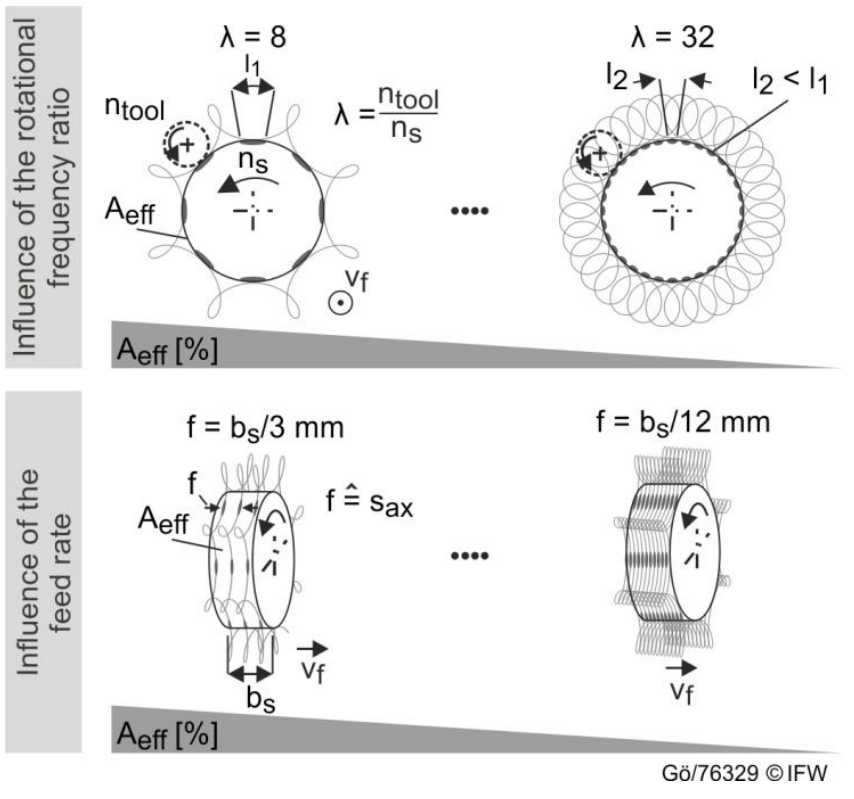

Fig. 4. Influence of the process parameters on the effective contact area

The effective contact area $\left(\mathrm{A}_{\text {eff }}\right)$ decreases when $\lambda$ is increased or when $f$ is reduced and is calculated by the following equation:

$$
A_{e f f}=100 *\left(1-\frac{A_{p a t}}{A_{s}}\right)
$$

with $A_{\text {pat }}$ being the size of a single elliptical pattern multiplied with the total number of pattern in turning direction $\left(\mathrm{X}_{\mathrm{pat}}\right)$ and feed direction $\left(\mathrm{Y}_{\mathrm{pat}}\right)$ :

$$
\begin{aligned}
& A_{\text {pat }}=\pi * \frac{1}{4}\left(b_{\text {pat }} * l_{\text {pat }}\right) * X_{\text {pat }} * Y_{\text {pat }} \\
& A_{\text {pat }}=\pi * \frac{1}{2}\left(b_{\text {pat }} * l_{\text {pat }}\right) * n_{\text {diam }} * \lambda * \frac{b_{s}}{f}
\end{aligned}
$$

and $\mathrm{A}_{\mathrm{s}}$ being the surface area of the cylindrical grinding wheel with the diameter $d_{s}$ and the wheel width $b_{s}$ :

$$
A_{s}=d_{s} * b_{s} * \pi
$$

A graphical visualization of the relation between the effect contact area $\left(A_{\text {eff), }}\right.$, the frequency ratio $(\lambda)$ and the feed rate (f) is shown in Fig. 5 and can be used for configuring $A_{\text {eff }}$ before each process.

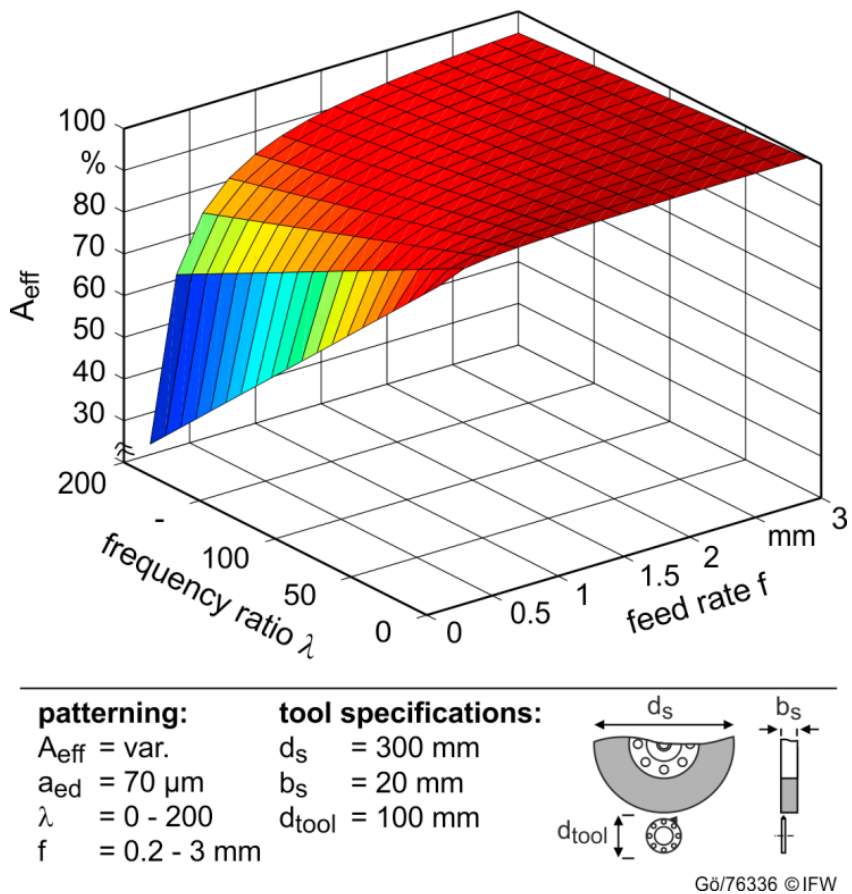

Fig. 5. The effective contact area $\left(\mathrm{A}_{\mathrm{eff}}\right)$ as a function of feed rate and frequency ratio

The pattern arrangement can also be influenced by turning the patterning spindle by $90^{\circ}$ to machine a crosswise pattern arrangement. The calculation of the contact conditions and the effective contact areas can be done according the previous equations. However the equations can even be simplified, since the pattern length crosswise is independent from the tool and grinding wheel frequency. Therefore $\alpha_{S}$ is equal to $\alpha_{\mathrm{S} 0}$ (compare equation 2 ).

\section{Influence of the grinding process parameter}

In order to investigate the influence of the grinding process parameters, when grinding with patterned grinding wheels, the effective contact area was held constant and the specific material removal rate $\mathrm{Q}^{\prime}{ }_{\mathrm{w}}$ was varied. An effective contact area of $\mathrm{A}_{\mathrm{eff}}=57 \%$ was machined with a frequency ratio of $\lambda=180$ and a feed rate of $\mathrm{f}=0,58 \mathrm{~mm}$. By increasing the feed rate from $600 \mathrm{~mm} / \mathrm{min}$ to $7200 \mathrm{~mm} / \mathrm{min}$ different material removal rates were realized. The grinding speed and the infeed were kept constant at $\mathrm{v}_{\mathrm{s}}=20 \mathrm{~m} / \mathrm{s}$ and $\mathrm{a}_{\mathrm{e}}=50 \mu \mathrm{m}$. Every experiment was repeated three times. In the following the mean values of all measurements are shown.

\subsection{Process forces}

In Fig. 6 the forces in normal $\left(F_{n}\right)$ and tangential $\left(F_{t}\right)$ direction during grinding are shown, when grinding with patterned and non-patterned grinding wheels. 


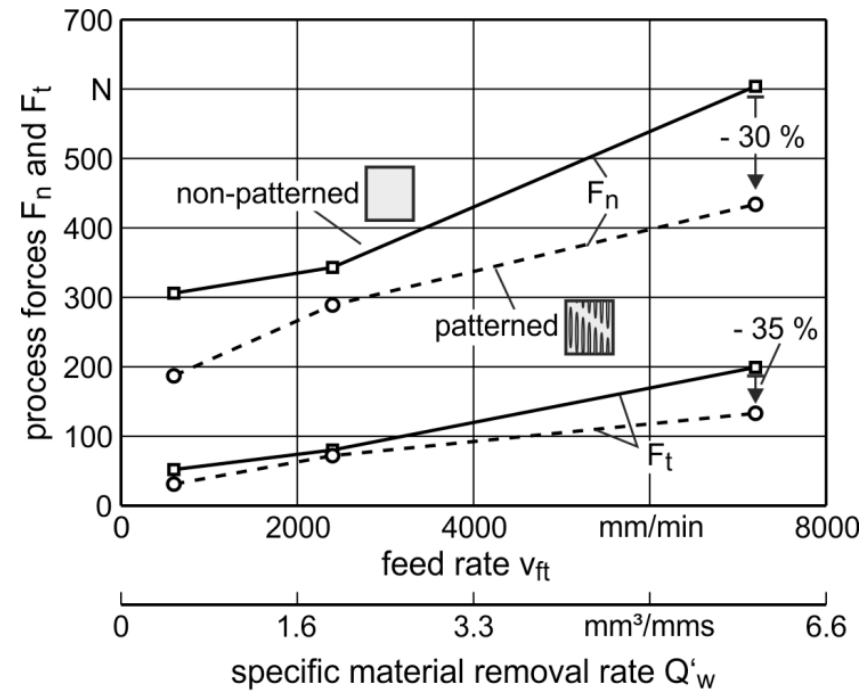

\begin{tabular}{lll}
\hline grinding: & patterning: & tool / workpiece: \\
face grinding & patterning tool & $\mathrm{Al}_{2} \mathrm{O}_{3}, \# 80$ \\
$\mathrm{v}_{\mathrm{S}}=20 \mathrm{~m} / \mathrm{s}$ & (1 diamond) & $1.2379,64 \mathrm{HRC}$ \\
$\mathrm{a}_{\mathrm{e}}=50 \mu \mathrm{m}$ & $\mathrm{A}_{\text {eff }}=57 \%$ & \\
$\mathrm{v}_{\mathrm{ft}}=600-7200 \mathrm{~mm} / \mathrm{min}$ & $\mathrm{a}_{\mathrm{ed}}=100 \mu \mathrm{m}$ & \\
& &
\end{tabular}

Fig. 6. Grinding forces when grinding with patterned and nonpatterned grinding wheels

During grinding with patterned wheels a process force reduction of up to $30 \%$ compared to a non-patterned standard grinding wheel was measured. The patterning process reduces the number of cutting edges and therefore the total amount of microscopic rubbing and ploughing effects, which directly influences the process forces.

The grinding process with patterned tools compared to nonpatterned grinding wheels is more effective, because more actual micro cutting occurs in the contact zone. This becomes obvious, when looking at the specific forces of these experiments shown in Fig. 7. The forces in normal and tangential direction from Fig. 6 were divided by the effective geometric contact area during grinding, which is the product of the geometric contact length $\left(1_{g}\right)$ and the width of cut $\left(a_{p}\right)$. The calculation is simplified by assuming that the grinding wheel is a cylinder volume element without pores. The effective contact area is $77.4 \mathrm{~mm}^{2}$ for the non-patterned grinding wheel and $44.1 \mathrm{~mm}^{2}$ for the patterned grinding wheel. In this graph, the specific forces of the patterned grinding wheel are significantly higher than the forces of the non-patterned wheel. The specific force can be described as a contact pressure on the grinding grains. When grinding with patterned grinding wheels, less grains remove the same material volume compared to the non-patterned grinding wheel, when $\mathrm{Q}^{\prime}{ }_{\mathrm{w}}$ is constant. The result is, that those grains penetrate deeper into the workpiece material, which decreases rubbing and ploughing effects and subsequently increases the grinding process efficiency. In conse- quence the surface roughness increases when grinding with patterned grinding wheel [15].

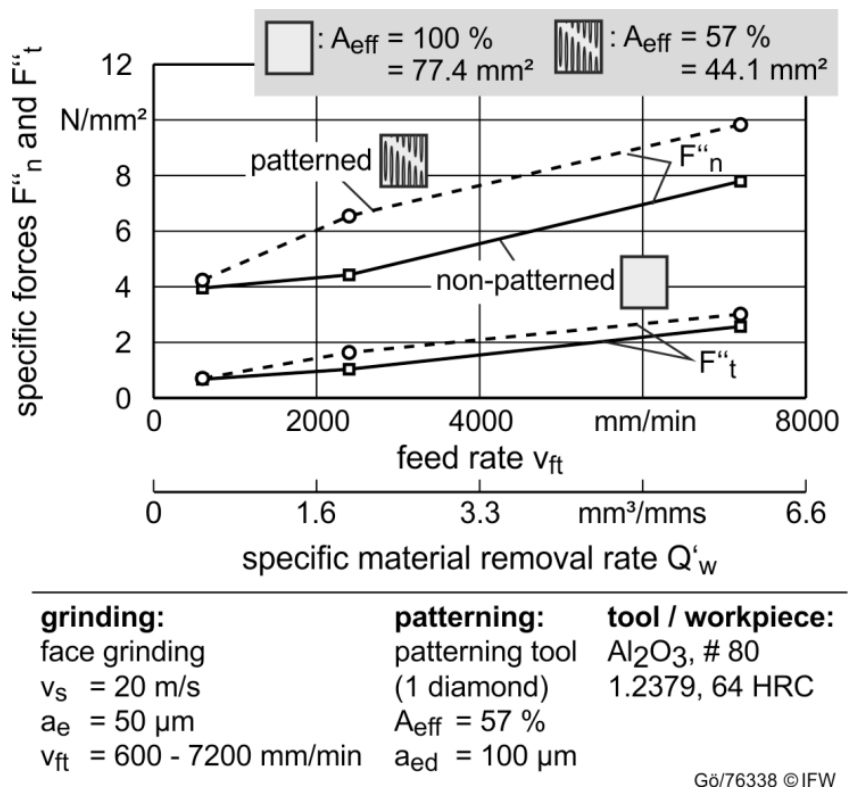

Fig. 7. Specific grinding forces when grinding with patterned and non-patterned grinding wheels

\subsection{Induced residual stresses}

The work piece quality, especially for grinding processes is an important factor. It can be divided into surface quality and subsurface quality. For analyzing the subsurface of the workpiece after grinding, induced residual stresses were measured and are presented in Fig. 8. The induced stresses change from compressive to tensile stresses, when the material removal rate increases. The increase of the mechanical load leads to a high thermal strain in the contact zone, which results in tensile stresses. When grinding with patterned grinding wheels more compressive stresses respectively less tensile stresses were measured. Looking at the images from the workpiece surface it becomes apparent, that less heat is generated in the contact when grinding with patterned grinding wheels, because the grinding burn intensity was significantly reduced. 


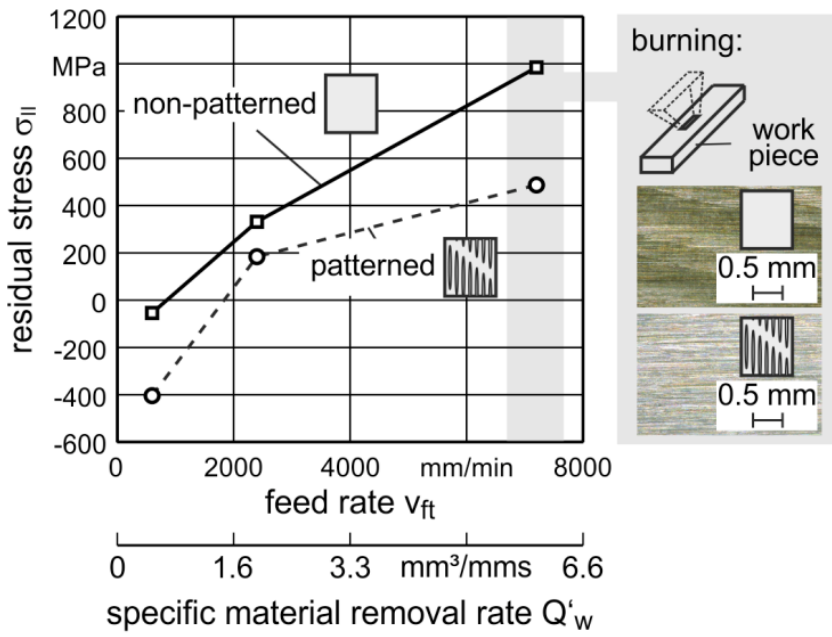

\begin{tabular}{lll}
\hline grinding: & patterning: & tool / workpiece: \\
face grinding & patterning tool & $\mathrm{Al}_{2} \mathrm{O}_{3}, \# 80$ \\
$\mathrm{v}_{\mathrm{S}}=20 \mathrm{~m} / \mathrm{s}$ & (1 diamond) & $1.2379,64 \mathrm{HRC}$ \\
$\mathrm{a}_{\mathrm{e}}=50 \mu \mathrm{m}$ & $\mathrm{A}_{\text {eff }}=57 \%$ & \\
$\mathrm{v}_{\mathrm{ft}}=600-7200 \mathrm{~mm} / \mathrm{min}$ & $\mathrm{a}_{\mathrm{ed}}=100 \mu \mathrm{m}$ & \\
& & Gö/76339 @IFW
\end{tabular}

Fig. 8. Induced residual stresses after grinding with patterned and non-patterned grinding wheels

This is due to two reasons. Firstly, as the process forces decrease, less grinding power is converted into heat. The second reason is assumed to be the improved coolant flow through the contact zone due to micro patterning. This aspect is addressed in the next chapter.

\subsection{Coolant flow through the contact zone}

In order to prove the assumption that patterned grinding wheels increase the coolant flow through the contact zone, analogy experiments were conducted with a coolant bin as described in chapter 2.

The results of the grinding tests are displayed in Fig. 9. Every experiment was repeated two times to consider statistical deviations. The mean variation is about $0.1 \mathrm{l} / \mathrm{min}$. Each graph displays the average values. In first tests the cutting speed $\mathrm{v}_{\mathrm{s}}$ was varied between $10 \mathrm{~m} / \mathrm{s}$ and $30 \mathrm{~m} / \mathrm{s}$. The coolant flow rate increases for both grinding tools. Both grinding tools have a certain amount of pores, which are equally distributed within the grinding wheel body. By increasing the grinding frequency the pores pass through the contact zone more often and increase the coolant transport capacity per time unit. The pattern act as artificial pores and increase the coolant flow even more compared to a non-patterned tool.

The influence of the radial feed rate is shown in Fig. 9, b). The coolant flow rate slightly increases, when raising the feed rate. An increase of the feed rate goes along with a higher specific material removal rate and higher mechanical load. In consequence the pressure between grinding wheel and workpiece in the contact zone rises. Consequently the coolant pressure in the pores and in the pattern rises as well, which increases the boiling point of the coolant fluid. Less coolant evaporates, when the feed rate is increased. Nevertheless the effect of the feed rate on the coolant flow rate is significantly smaller than the effect of the cutting speed. Similar to the results from the influence of the cutting speed, more coolant per minute was collected, when grinding with patterned grinding wheels.
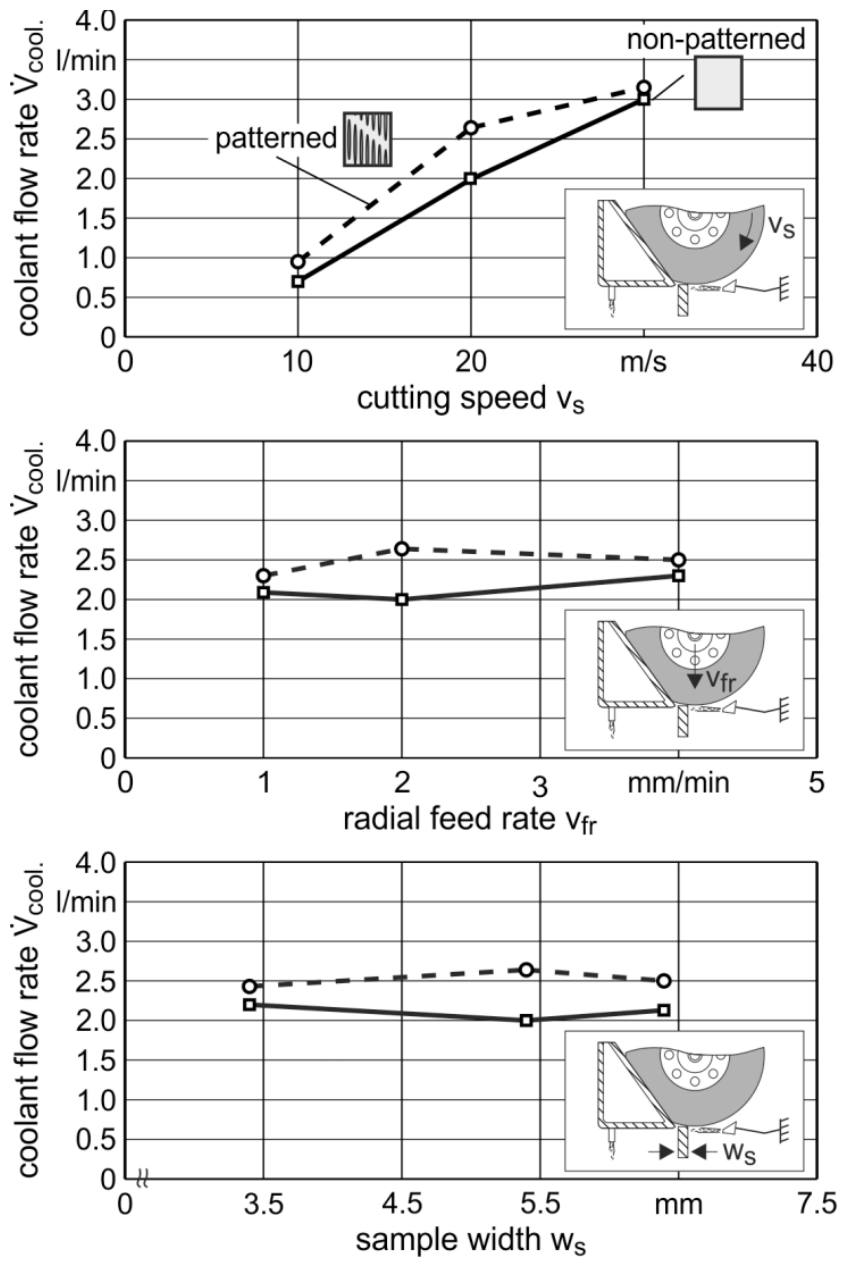

\begin{tabular}{lll}
\hline grinding: & patterning: & tool / workpiece: \\
plunge grinding & patterning tool & $\mathrm{Al}_{2} \mathrm{O}_{3}, \# 80$ \\
$\mathrm{~V}_{\mathrm{s}}=10-30 \mathrm{~m} / \mathrm{s}$ & (1 diamond) & $1.2379,64 \mathrm{HRC}$ \\
$\mathrm{W}_{\mathrm{s}}=3.4-6.4 \mathrm{~mm}$ & $\mathrm{~A}_{\text {eff }}=75 \%$ & \\
$\mathrm{~V}_{\mathrm{fr}}=1-4 \mathrm{~mm} / \mathrm{min}$ & $\mathrm{a}_{\mathrm{ed}}=70 \mu \mathrm{m}$ &
\end{tabular}

Fig. 9. Influence of the cutting speed a), feed rate b) and sample width c) on the coolant flow rate

The influence of the sample width $\mathrm{w}_{\mathrm{s}}$ on the coolant flow can be taken from Fig. 9, c). For non-patterned grinding wheels the coolant flow rate stays almost constant at about $2.1 \mathrm{l} / \mathrm{min}$, when changing the sample width. When grinding with patterned grinding wheels the flow rate through the 
contact zone is about $20 \%$ higher, but stays almost constant as well at about $2.5 \mathrm{l} / \mathrm{min}$.

The coolant bin experiments proved the assumption that patterned grinding wheels increase the coolant flow rate through the contact zone. Therefore patterning enables the reduction of grinding burn and tensile stresses by improving the cooling condition in the grinding contact zone.

\section{Influence of the pattern arrangement}

In order to investigate the influence of the pattern arrangement grinding experiments with different effective contact areas $\left(\mathrm{A}_{\text {eff }}\right)$ and pattern orientations were conducted. Effective contact areas of the grinding wheel of $90 \%, 82 \%$ and $75 \%$ have been realized by using a patterning tool with one diamond. All grinding results are compared to the results of grinding with a non-patterned grinding wheel (reference). Before each experiment all grinding wheels have been dressed in an identical way. The results of the face grinding experiments when changing the effective contact area are illustrated in Fig. 10.

During the tests the process parameters were kept constant at a cutting speed of $\mathrm{v}_{\mathrm{s}}=20 \mathrm{~m} / \mathrm{s}$, a feed rate of $\mathrm{v}_{\mathrm{w}}=2.400$ $\mathrm{mm} / \mathrm{min}$ and cutting depth of $\mathrm{a}_{\mathrm{e}}=50 \mu \mathrm{m}$. The results show the mean value of three experimental runs. The process forces in normal and tangential direction decrease significantly when the effective contact area is minimized from $90 \%$ to $75 \%$. Less active grains are involved in the grinding process. The contact pressure on the remaining grains rises, when $\mathrm{A}_{\text {eff }}$ decreases. Ploughing and rubbing processes are suppressed for the benefit of a more effective cutting process. Nevertheless the reduction of cutting edges goes along with an increase of the surface roughness, because less kinematic overlappings of cutting paths occur. As a result of reduced tangential forces, also less cutting power $\left(\mathrm{P}_{\mathrm{c}}\right)$ was necessary when grinding with a decreased effective contact area. The cutting power was calculated according to:

$$
P_{c}=F_{t} * v_{s}
$$

After grinding the work piece surface was analyzed optically and grinding burn marks have been correlated with a grinding burn intensity on a scale from 0 to $5(0=$ no burning, $5=$ severe burning). Less grinding burn was detected when grinding with patterned grinding wheels, due to an increased coolant flow rate through the contact zone (compare Fig. 9).

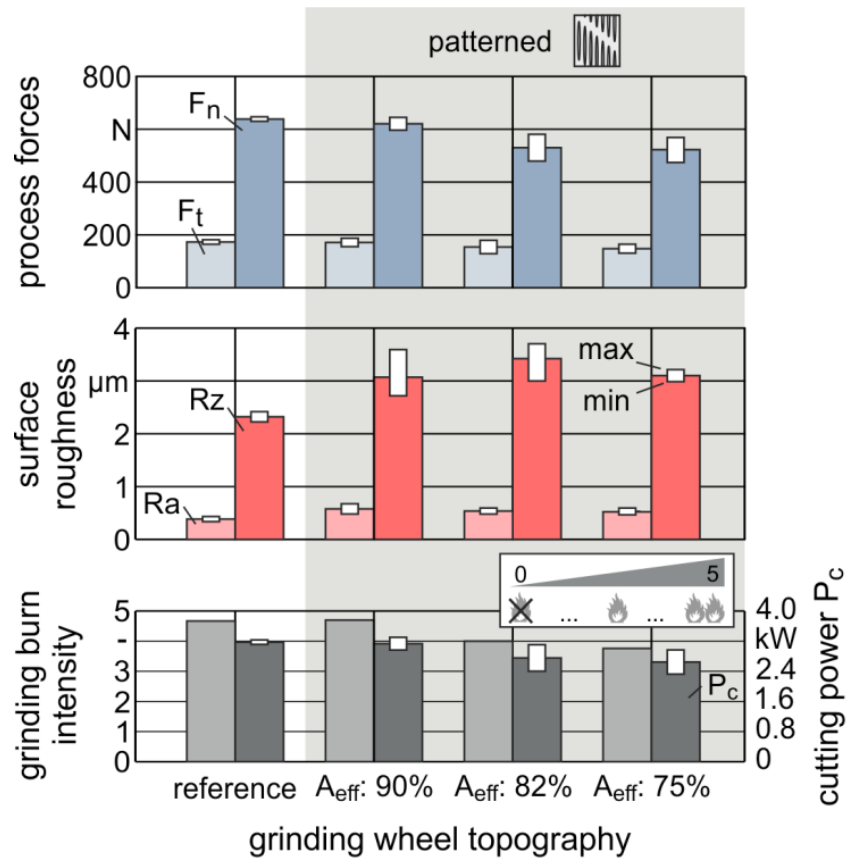

\begin{tabular}{lll}
\hline grinding: & patterning: & workpiece / tool: \\
face grinding & patterning tool & $\mathrm{Al}_{2} \mathrm{O}_{3}, \# 80$ \\
$\mathrm{v}_{\mathrm{S}}=20 \mathrm{~m} / \mathrm{s}$ & $(1$ diamond) & $1.2379,64 \mathrm{HRC}$ \\
$\mathrm{a}_{\mathrm{e}}=50 \mu \mathrm{m}$ & $\mathrm{A}_{\text {eff }}=\mathrm{var}$ & \\
$\mathrm{v}_{\mathrm{ft}}=2400 \mathrm{~mm} / \mathrm{min}$ & $a_{\text {ed }}=70 \mu \mathrm{m}$ &
\end{tabular}

Fig. 10. Influence of the effective contact area on process forces, surface roughness, grinding burn intensity and cutting power

In order to investigate the potential of a different pattern arrangement, a crosswise pattern alignment was machined, according to the patterning strategy explained in chapter 3 . The results of grinding tests with this orthogonally patterned wheels are shown in Fig. 11. Similar to the results with the straight pattern arrangement, process forces decrease, surface roughness rises, grinding burn and cutting power decrease when the number of pattern is increased. However it can be seen, that process force and grinding burn already significantly decrease for $A_{\text {eff }}=90 \%$, while the surface roughness stays nearly constant at about $\mathrm{Ra}=$ $0.5 \mu \mathrm{m}$ and $\mathrm{Rz}=4 \mu \mathrm{m}$. This can be explained by the orientation of pattern. Compared to the straight pattern arrangement the pattern are perpendicular to the dressing helix. Therefore the original grinding wheel topography created through dressing is less affected by the crosswise patterning process. At the same time the positive effects of the pattern shown in the previous results are also valid for this arrangement. 


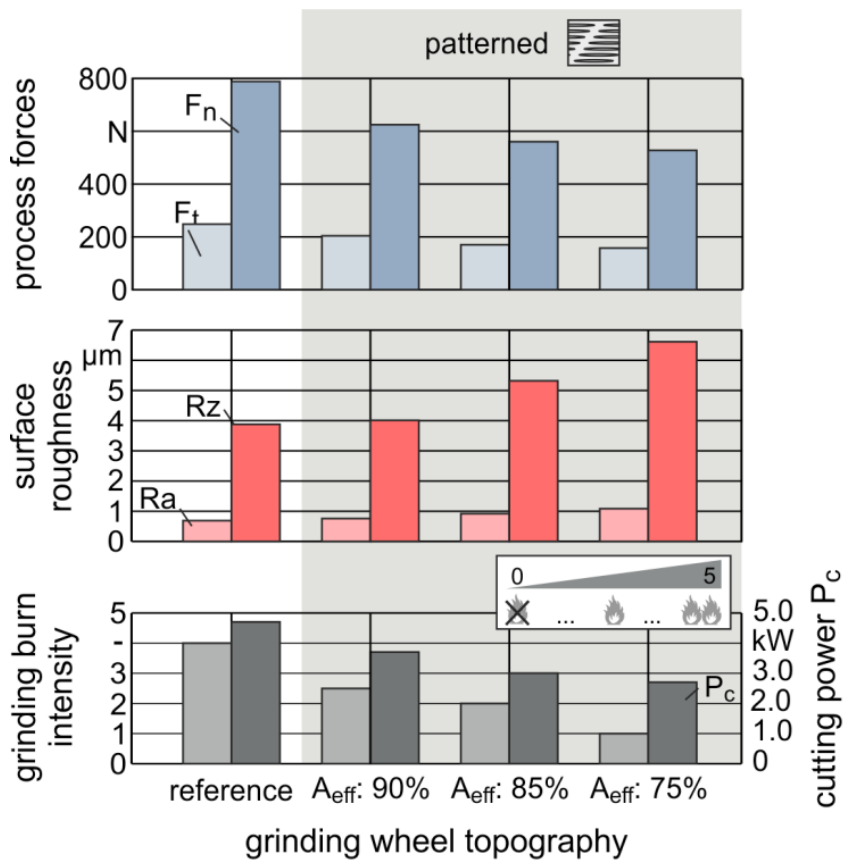

\begin{tabular}{lll}
\hline grinding: & patterning: & workpiece / tool: \\
face grinding & patterning tool & $\mathrm{Al}_{2} \mathrm{O}_{3}, \# 80$ \\
$\mathrm{v}_{\mathrm{S}}=20 \mathrm{~m} / \mathrm{s}$ & (8 diamonds) & $1.2379,64 \mathrm{HRC}$ \\
$\mathrm{a}_{\mathrm{e}}=50 \mu \mathrm{m}$ & $\mathrm{A}_{\text {eff }}=\mathrm{var}$. & \\
$v_{\mathrm{ft}}=6000 \mathrm{~mm} / \mathrm{min}$ & $\mathrm{a}_{\mathrm{ed}}=70 \mu \mathrm{m}$ &
\end{tabular}

Fig. 11. Influence of a crosswise pattern arrangement on the process force, surface roughness, grinding burn intensity and cutting power

\section{Influence of the tool specification}

The previous results showed great potential for enhancing the overall grinding performance by using patterned grinding wheels. In order to investigate the possibility for an industrial application of this technology in more detail, different grinding wheel specifications were tested. A roughing process was conducted by choosing a porous conventional grinding wheel with a grain size of \#54. The grinding wheel was dressed with a form roller with a $U_{d}=$ $6, \mathrm{q}_{\mathrm{d}}=0,8$. In contrast, a finishing process with a dense texture and fine grain size ( $\# 180)$ was used, dressed with $\mathrm{U}_{\mathrm{d}}=12$ and $\mathrm{q}_{\mathrm{d}}=0,8$.

The resulting process forces measured during the roughing process for patterned and non-patterned grinding wheels are shown in Fig. 12. Cutting speed and feed rate stayed constant at $v_{\mathrm{s}}=20 \mathrm{~m} / \mathrm{s}$ and $\mathrm{v}_{\mathrm{ft}}=6000 \mathrm{~mm} / \mathrm{min}$. Different specific material removal rates were realized by increasing the infeed from $\mathrm{a}_{\mathrm{e}}=25 \mu \mathrm{m}$ to $\mathrm{a}_{\mathrm{e}}=100 \mu \mathrm{m}$. The effective contact area $\left(\mathrm{A}_{\text {eff }}\right)$ stayed constant at $75 \%$. When grinding with patterned wheels, the process in normal and tangential direction could have been reduced by over $45 \%$.

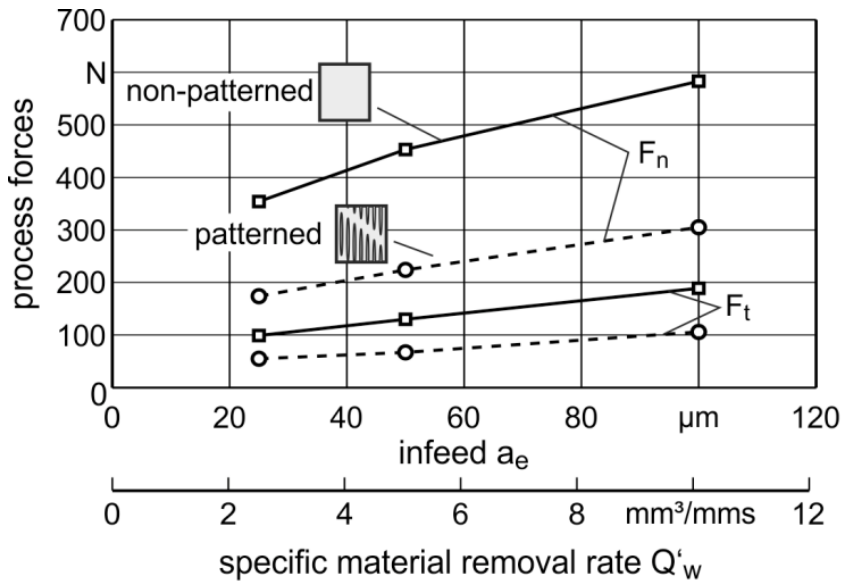

\begin{tabular}{lll}
\hline grinding: & patterning: & workpiece / tool: \\
face grinding & patterning tool & $\mathrm{Al}_{2} \mathrm{O}_{3}, \# 54$ \\
$\mathrm{v}_{\mathrm{s}}=20 \mathrm{~m} / \mathrm{s}$ & (1 diamond) & $1.2379,64 \mathrm{HRC}$ \\
$\mathrm{a}_{\mathrm{e}}=25-100 \mu \mathrm{m}$ & $\mathrm{A}_{\text {eff }}=75 \%$ & \\
$\mathrm{v}_{\mathrm{ft}}=6000 \mathrm{~mm} / \mathrm{min}$ & $\mathrm{a}_{\text {ed }}=70 \mu \mathrm{m}$ & \\
\end{tabular}

Fig. 12. Roughing - grinding with a porous grinding wheel with medium grain size

In contrast, the process forces during grinding with the dense textured grinding wheel only slightly decreased when patterned wheels were used (Fig. 13).

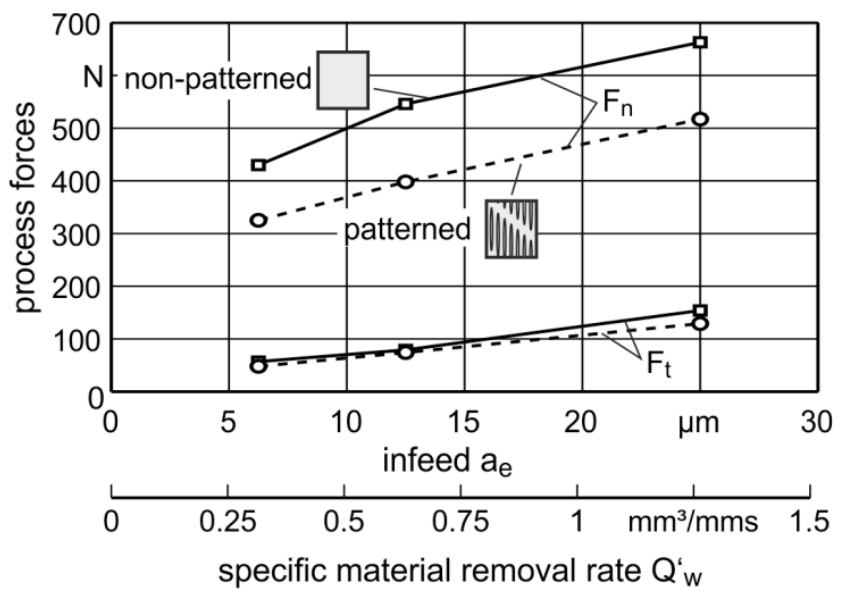

\begin{tabular}{lll}
\hline grinding: & patterning: & workpiece / tool: \\
face grinding & patterning tool & $\mathrm{Al}_{2} \mathrm{O}_{3}, \# 180$ \\
$\mathrm{v}_{\mathrm{S}}=20 \mathrm{~m} / \mathrm{s}$ & $(1$ diamond) & $1.2379,64 \mathrm{HRC}$ \\
$\mathrm{a}_{\mathrm{e}}=6.25-25 \mu \mathrm{m}$ & $\mathrm{A}_{\text {eff }}=75 \%$ & \\
$\mathrm{~V}_{\mathrm{ft}}=3000 \mathrm{~mm} / \mathrm{min}$ & $\mathrm{a}_{\text {ed }}=70 \mu \mathrm{m}$ & \\
\end{tabular}

Fig. 13. Finishing - grinding with a dense grinding wheel with a small grain size

The grinding was conducted with an infeed rising from $\mathrm{a}_{\mathrm{e}}=$ $6.25 \mu \mathrm{m}$ to $\mathrm{a}_{\mathrm{e}}=25 \mu \mathrm{m}$. Cutting speed and feed rate stayed constant at $\mathrm{v}_{\mathrm{c}}=20 \mathrm{~m} / \mathrm{s}$ and $\mathrm{v}_{\mathrm{ft}}=3000 \mathrm{~mm} / \mathrm{min}$. In this case the pattern are not able to clearly modify the topography of the grinding wheel. Compared to the roughing tool more grains are cut out by patterning due to a higher grain concentration per volume. Nevertheless, proportional to the 
total amount of grains, this amount is less for the finishing wheel. Therefore pattern have a larger impact on porous grinding wheels than on dense textured tools.

A similar conclusion can be drawn, when analyzing induced stresses near the subsurface and the grinding burn intensity for both grinding wheel specifications. For grinding with the roughing tool the induced stresses and the grinding burn intensity are significantly reduced for every specific material removal rate (Fig. 14). After grinding with the patterned grinding wheel no grinding burn marks were detected and compressive stresses from -390 MPa to around $-50 \mathrm{MPa}$ were measured. The patterns expose new deeper situated pores along the grinding wheel's intrinsic line by removing grains and bonding material. In consequence the coolant flow rate through the contact zone is increased and the chip transport is improved, which is beneficial for the thermo-dynamical load in the contact zone.
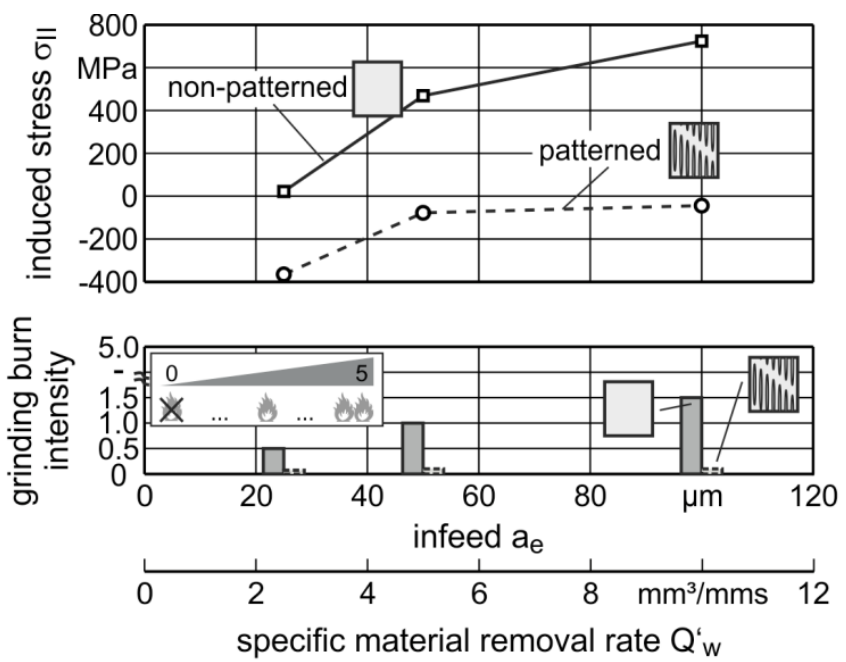

\begin{tabular}{lll}
\hline grinding: & patterning: & workpiece / tool: \\
face grinding & patterning tool & $\mathrm{Al}_{2} \mathrm{O}_{3}, \# 54$ \\
$\mathrm{v}_{\mathrm{s}}=20 \mathrm{~m} / \mathrm{s}$ & $(1$ diamond) & $1.2379,64 \mathrm{HRC}$ \\
$\mathrm{a}_{\mathrm{e}}=25-100 \mu \mathrm{m}$ & $\mathrm{A}_{\text {eff }}=75 \%$ & \\
$\mathrm{v}_{\mathrm{ft}}=6000 \mathrm{~mm} / \mathrm{min}$ & $\mathrm{a}_{\mathrm{ed}}=70 \mu \mathrm{m}$ &
\end{tabular}

Fig. 14. Roughing - induced stresses and grinding burn

When grinding with a dense textured grinding wheel with small grain sizes (finishing tool), this effect is also verified (Fig. 15). However, the reduction of induced stresses towards compressive stresses is minimal. The induced stresses develop from compressive stresses (-628 MPa) towards tensile stresses (561 MPa), when the specific material removal rate is increased from $\mathrm{Q}^{\prime}{ }_{\mathrm{w}}=0.25 \mathrm{~mm}^{3} / \mathrm{mms}$ to 1.25 $\mathrm{mm}^{3} / \mathrm{mms}$ for the non-patterned grinding wheel. The stress values for the patterned wheel are in average $90 \mathrm{MPa}$ less, which is within the range of the general mean deviation of every residual stress measurement (+/- $50 \mathrm{MPa})$. Regarding the grinding burn intensity, no clear difference is visually noticeable.
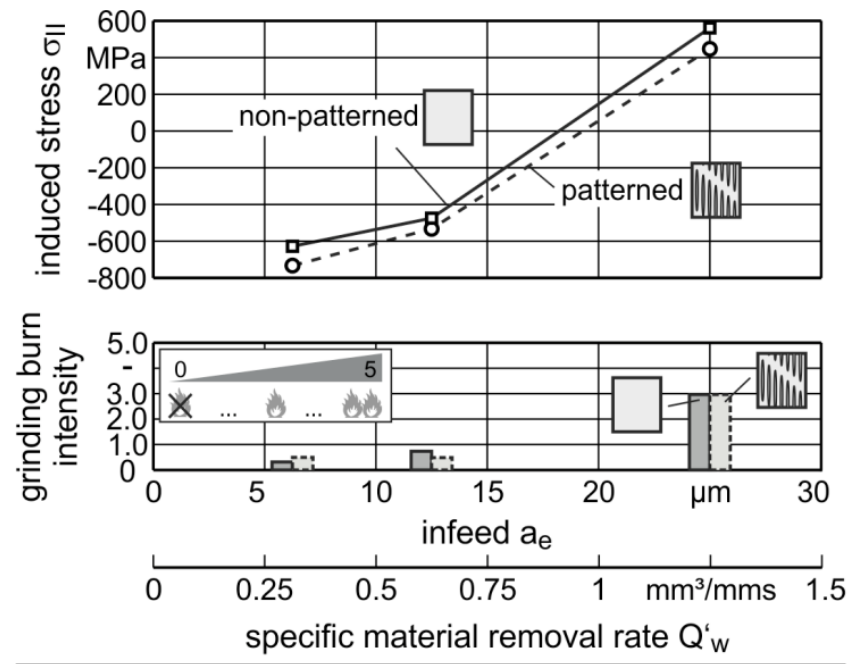

\begin{tabular}{lll}
\hline grinding: & patterning: & workpiece / tool: \\
face grinding & patterning tool & $\mathrm{Al}_{2} \mathrm{O}_{3}, \# 180$ \\
$\mathrm{v}_{\mathrm{S}}=20 \mathrm{~m} / \mathrm{s}$ & $(1$ diamond) & $1.2379,64 \mathrm{HRC}$ \\
$\mathrm{a}_{\mathrm{e}}=6.25-25 \mu \mathrm{m}$ & $\mathrm{A}_{\text {eff }}=75 \%$ & \\
$\mathrm{v}_{\mathrm{ft}}=3000 \mathrm{~mm} / \mathrm{min}$ & $\mathrm{a}_{\text {ed }}=70 \mu \mathrm{m}$ &
\end{tabular}

Fig. 15. Finishing - induced stresses and grinding burn

The results of the grinding experiments with different tool specifications reveal that the developed process characteristic $\mathrm{A}_{\text {eff }}$ is only valid for a specific tool specification. When comparing grinding results of patterned vitrified bonded grinding wheels the tool texture and grain size always have to be considered as well. As a result $\mathrm{A}_{\text {eff }}$ needs to be modified, also considering the tool specifications. Those specifications are standardized in DIN ISO 525. However, apart from the grain size no specification is quantifiable, since every grinding tool producer has its own definition for porosity, grain or secondary grain concentration. Therefore the grinding wheel topography of the tools used within this research are measured with a profilometer and AbbotFirestone curves are created for every tool. The height of centres (Rpk value) of the Abbot-Firestone curve is correlated with the average force reduction in normal direction realized with an effective contact area of $\mathrm{A}_{\text {eff }}=75 \%$. The height of centres enables a differentiation between a dense and porous textured grinding wheel. All three grinding wheels $(\# 54, \# 80, \# 180)$ were dressed with a form roller and a total specific material volume of $\mathrm{V}^{\prime}{ }_{\mathrm{w}}=400 \mathrm{~mm} / \mathrm{mm}$ was ground. The average force reduction in normal direction when grinding with a patterned tool compared to a non-patterned tool was measured for different specific material removal rates. The correlation between this average force reduction for every grinding wheel and the Rpk value is shown in Fig. 16. A line of best fit was set through the measured data to approximate the average force reduction for an ideal topography without any pores $(\mathrm{Rpk}=0 \mu \mathrm{m})$. As a result a shape factor for each tool $\left(\mathrm{k}_{\text {tool }}\right)$ can be calcu- 
lated, which correlates the actual grinding wheel topography with the ideal one.

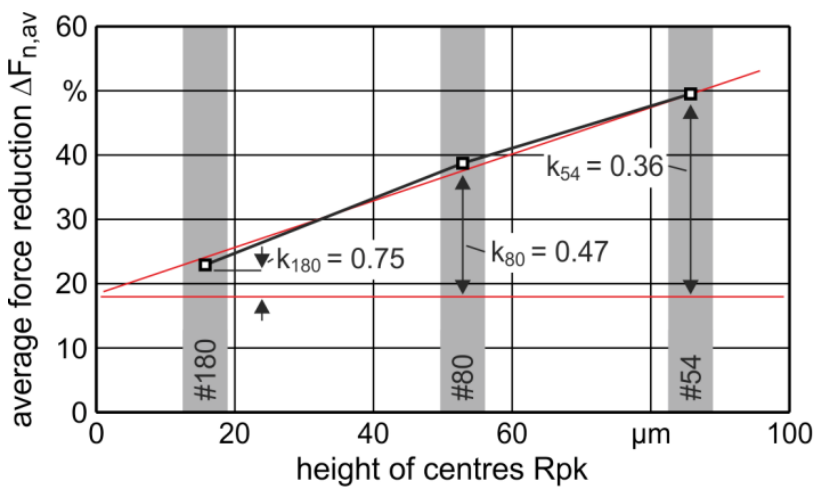

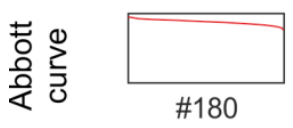

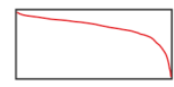

\#80

\section{grinding:}

face grinding

$\mathrm{v}_{\mathrm{S}}=20 \mathrm{~m} / \mathrm{s}$

$\mathrm{Q}_{\mathrm{w}}=$ var.

$\mathrm{V}_{\mathrm{w}}{ }_{\mathrm{w}}=400 \mathrm{~mm}^{3} / \mathrm{mm}$

$\begin{array}{ll}\text { patterning: } & \text { tool / workpiece: } \\ \text { patterning tool } & \mathrm{Al}_{2} \mathrm{O}_{3} \\ \mathrm{~A}_{\text {eff }}=75 \% & \text { grain size: var. } \\ \mathrm{a}_{\text {ed }}=70 \mu \mathrm{m} & \text { texture: var. } \\ & 1.2379,64 \mathrm{HRC} \\ & \end{array}$

Fig. 16. Calculation of the shape factor based on the topography of the grinding wheel

The shape factor for each tool $\left(\mathrm{k}_{\mathrm{tool}}\right)$ is multiplied with the effective contact area in order to compute a specific process characteristic $\mathrm{A}_{\mathrm{eff}, \mathrm{spec}}$ for every tool based an Rpk.

$$
A_{\text {eff }, \text { spec }}=k_{\text {tool }} * A_{e f f}
$$

Table 1. Shape factor for the grinding wheels

\begin{tabular}{c|c|c|c} 
tool & grain size & texture & $\mathrm{k}_{\text {tool }}$ \\
\hline standard & $\# 80(\sim 177 \mu \mathrm{m})$ & 5 & 0.47 \\
roughing & $\# 54(\sim 270 \mu \mathrm{m})$ & 8 & 0.36 \\
finishing & $\# 180(\sim 82 \mu \mathrm{m})$ & 2 & 0.75
\end{tabular}

Nevertheless the determination of $\mathrm{A}_{\mathrm{eff}, \mathrm{spec}}$ is not necessary, when grinding with only one grinding wheel specification regarding grain size and texture. In this case the faster and easier calculation of $\mathrm{A}_{\text {eff }}$ (see equation 4) is sufficient, since $\mathrm{A}_{\text {eff }}$ and $\mathrm{A}_{\text {eff,spec }}$ are linearly depended. If different tool specifications are tested, the Rpk value has to be measured and the shape factor $\left(\mathrm{k}_{\text {tool }}\right)$ has to be calculated according to Fig. 16.

\section{Tool wear}

An efficient future industrial application of the patterning technology is directly connected with the wear of the grinding wheel tool, due to patterning. In order to investigate the macroscopic grinding wheel wear, grinding test with different effective contact areas $\left(\mathrm{A}_{\text {eff }}\right)$ were conducted. Further- more the grinding wheel bonding was varied from soft to hard. The specific removed material volume was stepwise increased to $600 \mathrm{~mm}^{3} / \mathrm{mm}$, without dressing or patterning the grinding wheel in between. The radial wear of the grinding wheel was determined by grinding into a graphite plate and by measuring the worn plateau.

For all patterned and non-patterned grinding wheels, the radial wear increases during grinding. A reduction of the effective contact area or rather an increase of the number of pattern leads to an increased radial wear progress. Especially the change from $\mathrm{A}_{\text {eff }}=82 \%$ to $75 \%$ leads to an extensive increase of the wear gradient. While the radial wear at $\mathrm{A}_{\text {eff }}=82 \%$ and $\mathrm{V}^{\prime}{ }_{\mathrm{w}}=600 \mathrm{~mm}^{3} / \mathrm{mm}$ increases only by $6 \mu \mathrm{m}$ compared to the non-patterned reference. The radial wear at $\mathrm{A}_{\text {eff }}=75 \%$ increases by $79 \mu \mathrm{m}$. The larger contact pressures per grain of the patterned wheels also increase the bonding load and therefore the chance of bonding failure. Therefore more grains and bonding material are released compared to the non-patterned tool. At $\mathrm{A}_{\text {eff }}=75 \%$ the radial wear continuously increases, when the specific removed material $\mathrm{V}^{\prime}{ }_{\mathrm{w}}$ is enhanced even after reaching the pattern depth. This can be explained by the grain size with $\mathrm{d}_{\mathrm{g}}=177 \mu \mathrm{m}$, which is larger than the pattern depth. Therefore, if whole grains are removed during patterning, the effective pattern depth is larger than the theoretical pattern depth $\left(\mathrm{a}_{\mathrm{ed}}=70 \mu \mathrm{m}\right)$. At a high pattern density $\left(\mathrm{A}_{\mathrm{eff}}=75 \%\right)$, this effect occurs more often compared to less patterned wheels. As a result, even at $\mathrm{V}^{\prime}{ }_{\mathrm{w}}=600 \mathrm{~mm}^{3} / \mathrm{mm}$ the influence of the patterning is still present, so that the radial wear still rises until the grinding wheel topography is entirely levelled.

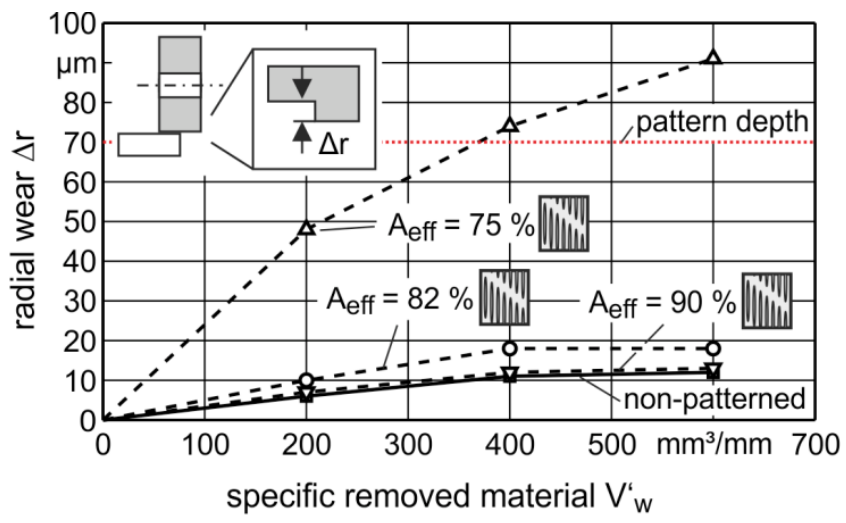

\begin{tabular}{|c|c|c|}
\hline $\begin{array}{l}\text { grinding: } \\
\text { face grinding } \\
\mathrm{v}_{\mathrm{S}}=20 \mathrm{~m} / \mathrm{s} \\
a_{\mathrm{e}}=50 \mu \mathrm{m} \\
\mathrm{V}_{\mathrm{ft}}=2400 \mathrm{~mm} / \mathrm{min} \\
\mathrm{V}_{\mathrm{w}}=0-600 \mathrm{~mm}^{3} / \mathrm{mm}\end{array}$ & $\begin{array}{l}\text { patterning: } \\
\text { patterning tool } \\
\text { ( } 8 \text { diamonds) } \\
A_{\text {eff }}=\text { var. } \\
a_{\text {ed }}=70 \mu \mathrm{m}\end{array}$ & $\begin{array}{l}\text { workpiece / tool: } \\
\mathrm{Al}_{2} \mathrm{O}_{3}, \# 80 \\
1.2379,64 \mathrm{HRC}\end{array}$ \\
\hline
\end{tabular}

Fig. 17. Radial grinding wheel wear when grinding with different effective contact areas 
The influence of the bonding strength (according to DIN ISO 525) on the grinding wheel wear in dependency of the contact area is shown in Fig. 18. A soft bonding (F) has the lowest grain retention force, so that the highest radial wear amount was measured for every contact area. An interesting fact is that the wear of the soft bonding at $\mathrm{A}_{\text {eff }}=82 \%$ and $75 \%$ after grinding $\mathrm{V}^{\prime}{ }_{\mathrm{w}}=400 \mathrm{~mm}^{3} / \mathrm{mm}$ is higher than the pattern depth with $\mathrm{a}_{\mathrm{ed}}=70 \mu \mathrm{m}$. The whole patterned area is removed due to wear and the grinding wheel is continuously renewing its topography through self-sharpening. The patterning created an open and aggressive grinding wheel topography that is favorable for self-sharpening. Nevertheless, the continuous self-preservation of this rough topography can be credited to the soft bonding. In comparison, the strongest bonding (M) shows the smallest radial wear after $\mathrm{V}^{\prime}{ }_{\mathrm{w}}=400 \mathrm{~mm} / \mathrm{mm}$, because of high grain retention forces. As a consequence the grains get blunted and flattened, which increases process forces and grinding burn on the workpiece. Therefore a grinding wheel with a mean bonding strength should be used, given the fact that selfsharpening and profile stability are equally balanced.

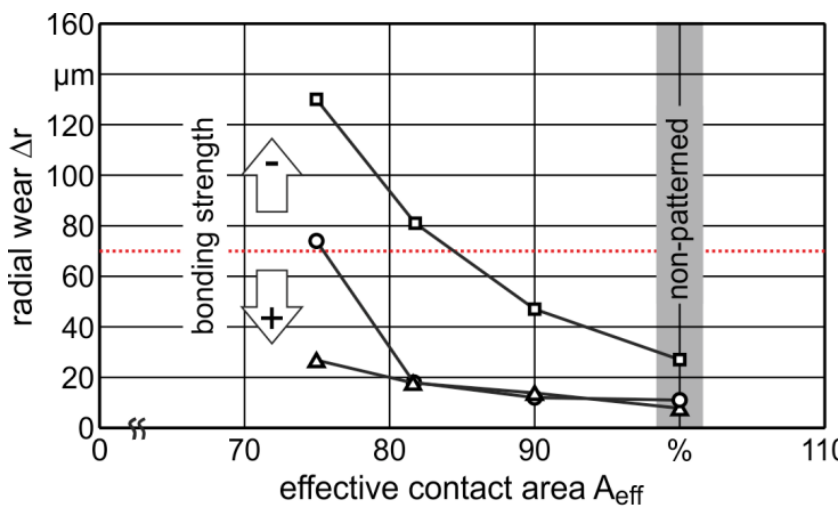

\begin{tabular}{lll}
\hline grinding: & patterning: & workpiece / tool: \\
face grinding & patterning tool & $\mathrm{Al}_{2} \mathrm{O}_{3}, \# 80$, \\
$\mathrm{V}_{\mathrm{S}}=20 \mathrm{~m} / \mathrm{s}$ & (8 diamonds) & bonding: $\mathrm{F}, \mathrm{J}, \mathrm{M}$ \\
$\mathrm{a}_{\mathrm{e}}=50 \mu \mathrm{m}$ & $\mathrm{A}_{\text {eff }}=\mathrm{var}$. & $1.2379,64 \mathrm{HRC}$ \\
$\mathrm{V}_{\mathrm{ft}}=2400 \mathrm{~mm} / \mathrm{min}$ & $\mathrm{a}_{\mathrm{ed}}=70 \mu \mathrm{m}$ & \\
$\mathrm{V}_{\mathrm{w}}^{\mathrm{s}}=400 \mathrm{~mm} / \mathrm{mm}$ & & Gö/76362 @IFW
\end{tabular}

Fig. 18. Radial grinding wheel wear when grinding with different bonding strength

\section{Conclusion and outlook}

In this paper a new and innovative method for the structuring of grinding wheels was introduced. The method is based on fly-cutting kinematics. The effective contact area $\left(\mathrm{A}_{\text {eff }}\right)$ was introduced as a patterning process characteristic that is used for designing the grinding wheel topography. Face grinding experiments showed that patterned grinding wheels have the potential to significantly decrease the mechanical and thermal load in the contact zone. Process force reductions of up to $30 \%$ and a coolant flow rate increase of up to $25 \%$ have been measured. The reduction of grinding burn and tensile stresses can be explained by improved micro cutting processes and coolant flow rates through the contact zone. This effect was proven with a specially designed coolant collecting bin.

In further grinding experiments the influence of the pattern arrangement was investigated. Changing the pattern direction from straight to a crosswise arrangement is beneficial regarding the surface roughness of the workpiece. Only a slight increase of the roughness was measured when grinding with a crosswise patterned wheel, compared to a nonpattern tool. An enhancement of the pattern density by reducing the effective contact area $\left(\mathrm{A}_{\text {eff }}\right)$, decreases process forces, grinding burn and induced tensile stresses but increases the surface roughness. Nevertheless, a smaller effective contact area also increases the grinding wheel wear, which should be considered when applying patterning for an industrial process. The introduced patterning method shows great potential to enhance the grinding performance of thermodynamically stressed grinding processes, such as creep feed grinding of superalloys, profile grinding of gears or plunge grinding or crankshafts. An advantage of this patterning method is that only certain areas of the grinding wheel can be patterned to partially reduce the grinding burn for example. Especially for porous grinding wheels patterning is an easy but yet effective method for increasing the coolant flow and chip transport, so that the overall grinding performance can be improved.

\section{Acknowledgements}

The presented investigations were undertaken with support of the German Research Foundation (DFG) and the São Paulo Research Foundation (FAPESP) within the joint project "Enhanced Grinding Performance by Means of Microdressed Grinding Wheels" (DE447/97-1) between the Institute of Production Engineering and Machine Tools (University of Hannover, Germany) and the Laboratory for Optimization of Manufacturing Processes (University of São Paulo, Brazil).

\section{References}

[1] Tönshoff, H., Denkena, B. (2013) Basic of cutting and abrasive processes. Lecture Notes in Production Engineering. Springer

[2] Noyen, M. (2008) Analyse der mechanischen Belastungsverteilung in der Kontaktzone beim Längs-UmfangsPlanschleifen. Dr.-Ing. dissertation, Universität Dortmund

[3] Herzenstiel, P., Aurich, J.C. (2010) CBN-grinding wheel with a defined grain pattern - extensive numerical and experimental studies. Machining Science and Technology 14:301-322 
[4] Uhlmann, E., Mewis J., Hochschild, L. (2010) Analyse von Schleifprozessen mit genuteten Schleifscheiben - Gegenüberstellung experimenteller und simulativer Untersuchungen. wt Werkstatttechnik online 100/6:494 - 501

[5] Uhlmann, E., Hochschild, L. (2013) Tool optimization for high speed grinding. Production Engineering Research and Development, Volume 7, Issue 2-3:185-193

[6] Nguyen, T., Zhang, L.C. (2009) Performance of a new segmented grinding wheel system. International Journal of Machine Tools and Manufacture, 49:291-296

[7] Tawakoli, T., Westkämper, E., Rabiey, M. (2007) Dry grinding by special conditioning. International Journal of Advanced Manufacturing Technologies, 33:419-424

[8] Tawakoli, T. (2010) T-Dress, Optimierung der Abrichtprozesse durch innovative Abrichtrolle mit Punktkontakt. dihw Magazin, 3.2010:34 - 42

[9] Da Silva, E., Oliveira, J., Salles, B., Cardoso, R., Reis, V. (2013) Strategies for production of parts textured by grinding using patterned wheels. CIRP Annals - Manufacturing Technology, 62(1):355-358

[10] Stepien, P. (2009) Regular surface texture generated by special grinding process. Journal of Manufacturing Science and Engineering, 131:011015-1 - 011015-7

[11] Denkena, B., Köhler, J., Kästner, J., Göttsching, T., Dinkelacker, F., Ulmer, H. (2013) Efficient machining of microdimples for friction reduction. Journal of Micro and Nano-Manufacturing, 1:011003-1 - 011003-8

[12] Oliveira J., Bottene A., Franca T. (2010) A Novel Dressing Technique for texturing of Ground Surfaces. CIRP Annals - Manufacturing Technology, 59(1):361-364

[13] Müller, N. (2001) Ermittlung des Einsatzverhaltens von Sol-Gel-Korund Schleifscheiben, Dr.-Ing. dissertation RWTH Aachen

[14] Grün, F. (1988) Kinematische und technologische Grundlagen der Fräsabrichtens, Fortschritts-Bericht VDI Reihe Nr. 152, VDI-Verlag, Kaiserslautern

[15] Denkena, B, Köhler, J., Göttsching, T. (2013) Influence of micro patterned grinding wheels on the work piece quality. Proceedings of the 13th euspen International Conference, May 2013, Berlin, 249-252 